\title{
Impact of educational intervention on the pattern and incidence of potential drug-drug interactions in Nepal
}

\author{
Durga BISTA, Archana SAHA, Pranaya MISHRA, Subish PALAIAN, Pathiyil R. SHANKAR.
} Received (first version): 24-Feb-2009 Accepted: 3-Oct-2009

\begin{abstract}
${ }^{*}$
Objective: To study the impact of educational intervention on the pattern and incidence of potential drug-drug interactions (DDIs). Method: All patients admitted to Internal Medicine wards of Manipal Teaching Hospital during the study period were included. Patient details were collected using a patient profile form and the datum from the filled forms was analyzed using Micromedex electronic database. An intervention was carried out through a presentation during clinical meeting and personal discussion. The target groups for the intervention included doctors and the nurses.

Results: Altogether 435 patients during preintervention and 445 during postintervention were studied. The incidence of potential DDIs was 53\% (preintervention) and 41\% (postintervention) [chi-square $=11.27, p=0.001$ ]. The average number of drugs per patient was 8.53 (pre-intervention) and 7.32 (post-intervention) [t=3.493, $p=0.001]$. Sixtyfour percent of the potential DDIs were of 'Moderate' type and 58\% had a 'Delayed' onset in both the phases. Seventy percent of the potential DDIs during the pre-intervention phase and $61 \%$ during post-intervention phase had a 'Good' documentation status. Pharmacokinetic mechanism accounted for $45 \%$ of the potential DDIs during preintervention and $36 \%$ in the post-intervention phase. Cardiovascular drugs accounted for $36 \%$ of the potential DDIs during pre-intervention and $33.2 \%$ during post-intervention phase. Furosemide was the high risk drug responsible for DDIs in both phases. The most common potential DDIs observed were between amlodipine and atenolol (4.82\%) (preintervention) and frusemide and aspirin (5.20\%) (postintervention).

Conclusion: There was an association between potential DDIs and age, sex, and polypharmacy.
\end{abstract}

\footnotetext{
*Durga BISTA. B.Pharm. Department of Pharmacology, Manipal College of Medical Sciences. Pokhara (Nepal). Archana SAHA. MD. Department of Pharmacology, Manipal College of Medical Sciences. Pokhara (Nepal). Pranaya MISHRA. PhD. Department of Hospital and clinical pharmacy, Manipal Teaching Hospital. Department of Pharmacology, Manipal College of Medical Sciences. Pokhara (Nepal).

Subish PALAIAN. MPharm. Department of Hospital and clinical pharmacy, Manipal Teaching Hospital. Department of Pharmacology, Manipal College of Medical Sciences. Pokhara (Nepal).

Pathiyil R. SHANKAR. MD. Department of Pharmacology, Manipal College of Medical Sciences. Pokhara (Nepal).
}

Keywords: Drug Interactions. Inpatients. Education, Continuing. Nepal.

\section{IMPACTO DE UNA INTERVENCION EDUCATIVA EN EL ESQUEMA E INCIDENCIAS DE INTERACCIONES MEDICAMENTOSAS POTENCIALES EN NEPAL}

\section{RESUMEN}

Objetivo: Estudiar el impacto de una intervención educativa en el esquema y la incidencia de las interacciones medicamentosas potenciales (DDI). Método: Se incluyó a todos los pacientes que visitaron el servicio de medicina interna del Hospital Universitario de Manipal. Los detalles de los pacientes se recogieron utilizando un formulario de perfil de paciente y los datos fueron analizados utilizando la base de datos electrónica Micromedex. Se realizó una intervención mediante una reunión clínica y discusión personal. El grupo diana eran los médicos y los enfermeros.

Resultados: Se estudiaron 435 pacientes durante la pre-intervención y 445 durante la post-intervención. Las incidencia de DDI potenciales fue del 53\% (pre-intervención) y 41\% (post-intervención) [chi cuadrado $=11,27, \mathrm{p}=0,001]$. La media de medicamentos por paciente fue de 8,53 (preintervención) y 7,32 (post-intervención) $[\mathrm{t}=3,493$, $\mathrm{p}=0,001]$. El $64 \%$ de las DDI potenciales eran de tipo 'Moderadas' y el 58\% tenía una iniciación 'Retrasada' en ambas fases. El 70\% de las DDI potenciales durante la fase de pre-intervención y el $61 \%$ en la post-intervención tenían un estado de documentación 'Bueno'. Mecanismos farmacocinéticos contabilizaron el $45 \%$ de las DDI potenciales durante la pre-intervención y el 36 en la post-intervención. Los medicamentos cardiovasculares sumaron el 36\% de las DDI potenciales durante la pre-intervención y el 33,2\% en la post-intervención. La furosemida fue el de mayor riesgo de DDI en las dos fases. La DDI potencial más comúnmente observada en la preintervención fue entre amlodipino y atenolol $(4,82 \%)$, y en la post-intervención fue entre furosemida y aspirina $(5,29 \%)$.

Conclusión: Existía una asociación entre DDI potencial y edad, sexo y polimedicación.

Palabras clave: Interacciones medicamentosas. Pacientes hospitalizados. Formación continuada. Nepal. 


\section{INTRODUCTION}

With the increase in the number of patients with multiple diseases and complex therapeutic regimens, polypharmacy becomes unavoidable. ${ }^{1}$ Drug-drug interactions (DDIs) are increasingly an important cause of Adverse Drug Reactions (ADRs). DDIs are often predictable and hence preventable. ${ }^{1}$ The most current JNC VII guidelines have recommended combination of medications for the management of diseases such as hypertension. ${ }^{2}$ The use of drug combinations are thus becoming unavoidable and can further increase the risk of DDIs. Evidence from epidemiologic studies suggests that DDIs contribute to significant number of adverse events in hospitalized patients. ${ }^{3}$ It is estimated to account for $6-30 \%$ of all $\mathrm{ADRs}^{4}$ and significant hospitalizations. ${ }^{5}$

A drug interaction (DIs) is said to occur when the effects of one drug are changed by the presence of another drug, food, drink or an environmental chemical agent. The result of Dls may be an additive effect, antagonism, alteration of effect or idiosyncratic effects. ${ }^{6}$ In general, patients on multiple drugs, elderly and seriously ill patients are more susceptible to DDIs. One hospital study found an ADR rate of $7 \%$ in patients taking 6-10 drugs, which increased to $40 \%$ in those taking 16-20 drugs. $^{7} \quad$ A Nepalese study showed a high prevalence of polypharmacy. During the hospital stay, $73 \%$ of patients received more than five, $54 \%$ received more than eight, and $24 \%$ received more than nine drugs concurrently. ${ }^{8}$ Data regarding the pattern and incidence of DDIs are lacking in Nepal. Hence the present study was conducted a) to identify the potential DDIs and to categorize them based on their severity, onset, and documentation status, b) to study the association of potential DDIs with patient demographics, disease state, and number of drugs per prescription and c) to study the outcome of an educational intervention on the pattern of potential DDIs.

\section{METHODS}

Settings: Prospective-interventional study carried out in the Internal Medicine wards (approximately 200 beds) (Intensive Care Unit (ICU), Special ward, Private ward, and General Medicine ward) of the Manipal Teaching Hospital (MTH), Pokhara, Nepal for six months. MTH is a tertiary care teaching hospital having bed occupancy of 550 beds. The six months were divided into pre-intervention (3 months), intervention (1 month) and postintervention phase (2 months). During the study, all patients who were admitted to the Internal Medicine wards were included. Patients admitted to wards other than the internal medicine wards, patients taking only one drug, patients on herbal drugs and patients on multivitamins were excluded. A self developed structured patient profile form was used for the collection of patient details. Micromedex electronic database was used for finding DDIs.
Micromedex electronic database ${ }^{9}$ : Micromedex categorizes DDIs on the basis of their severity, onset and documentation. It also provides the mechanism of the DDIs, clinical outcomes and management of the DDI. 'Severity', 'Onset' and the 'Documentation' status are defined by Micromedex in the following way.

Severity: The 'Major' DDIs may be life threatening and/or require medical intervention to minimize or prevent serious adverse effects. The 'Moderate' one may result in an exacerbation of the patient's condition and/or require an alteration in therapy. The 'Minor' DDIs, would have limited clinical effects.

Onset: The 'Rapid' onset type of DDIs leads to the clinical conflict or adverse effects within 24 hours following drug administration. The 'Delayed' onset type does not lead to the onset of clinical conflict or adverse effects appear within the first 24 hours following drug administration.

Documentation status: The 'Excellent' documentation status is the one for which controlled studies have clearly established the existence of the interaction. 'Good' documentation strongly suggests the interaction exists, but well-controlled studies are lacking. In case of 'Fair' documentation, available documentation is poor, but pharmacologic considerations lead doctors to suspect the interaction exists; or, documentation is good for a pharmacologically similar drug. In 'Poor' documentation, documentation is poor, such as limited case reports; but, the clinical conflict is theoretically possible. Lastly, in 'unlikely' documentation, documentation is poor and lacks a sound pharmacological basis.

Operational modality: The study was carried out in three phases pre-intervention, intervention and post-intervention.

Phase I: Pre-intervention phase (February 12-May 12, 2006): The Investigator (Post-graduate student in Pharmacology) attended daily ward rounds with the doctors in the internal medicine wards. The patient information, drug regimen and related parameters were entered in the designed structured patient profile form. DDls were found using the electronic database i.e. Micromedex. Data was analyzed using an Excel sheet and a 'preintervention report' was made. The pre-intervention report included the following: age, sex, diseases, average number of drug per patient, potential DDIs in smokers and alcoholics, and severity, onset, documentation status, and mechanism of potential DDIs. The report also listed the highest risk drugs and highest risk interaction found during the preintervention phase.

Phase II: Intervention phase (May 13-June 13, 2006): The 'pre-intervention report' was first brought to the notice of the hospital administration and presented in the weekly held clinical meeting of the hospital. During the meeting, the pre-interventional findings were presented to the doctors through a 'Talk program on drug interactions'. The presentation covered the theoretical aspects of DDIs along with the pre-intervention findings. All the concerned department heads, consultants, medical 
officers and interns were invited through a circular. Majority of the participants during the program were from the Medicine department (a total of seven among the eight consultants, the head of the department, three among the four medical officers and one among the two interns participated from the medicine department). All the participants were provided with a copy of the pre-intervention result. Nurses were also briefed regarding the finding of DDIs.

Phase III: Post-intervention phase (July 23 September 23, 2006): Post-intervention phase was conducted identically as the pre-intervention phase. After completing the data collection, the impact and outcomes of intervention on the pattern of potential DDIs was found comparing both the pre and post intervention data.

Statistical analysis: The results obtained from pre and post-intervention studies were analyzed and compared using Excel, SPSS (version 9) and Epilnfo6 programs. Statistics (chi-square and unpaired t tests) were applied for the comparison. A ' $P$ ' value less than 0.05 was considered significant.

\section{RESULTS}

During the pre-intervention phase, 435 patients (prescribed 1,953 drugs) and during the postintervention phase 445 patients (prescribed 1357 drugs) were studied. Among these patients, 53\% $(n=435)$ during the pre-intervention and $41 \%$ $(n=445)$ during the post-intervention were at risk of developing at least one potential DDI during their hospital stay (chi-square=11.27, $\mathrm{p}=0.003$ ). Altogether 622 potential DDIs in the pre-intervention and 423 potential DDIs in the post-intervention phase were identified.

The average number of drugs prescribed among the patients who were at risk of developing DDIs was $8.53(\mathrm{SD}=4.03) \quad$ (pre-intervention) and 7.32 $(\mathrm{SD}=3.01)$ (post-intervention). There was significant $(\mathrm{t}=4.646, \mathrm{p}=0.001)$ reduction in the overall number of drugs prescribed following the intervention.

\begin{tabular}{|c|c|c|c|c|}
\hline \multicolumn{5}{|c|}{ Table 1: Age distribution } \\
\hline \multicolumn{3}{|c|}{ Pre-intervention $(n=435)$} & \multicolumn{2}{|c|}{$\begin{array}{l}\text { Post-intervention } \\
(\mathrm{n}=445)\end{array}$} \\
\hline $\begin{array}{c}\text { Age } \\
\text { (years) }\end{array}$ & $\begin{array}{l}\text { Risk for } \\
\text { DDIs } \\
(\%)\end{array}$ & $\begin{array}{c}\text { Total } \\
\text { patients } \\
(\mathrm{n}=435)\end{array}$ & $\begin{array}{l}\text { Risk for } \\
\text { DDIs } \\
(\%)\end{array}$ & $\begin{array}{c}\text { Total } \\
\text { patients } \\
(\mathrm{n}=445)\end{array}$ \\
\hline $11-20$ & $9(27)$ & 33 & $7(18)$ & 39 \\
\hline $21-30$ & $13(27)$ & 48 & $8(16)$ & 49 \\
\hline $31-40$ * & $15(54)$ & 28 & $8(21)$ & 39 \\
\hline $41-50$ & $22(39)$ & 56 & $29(51)$ & 57 \\
\hline $51-60$ & $38(51)$ & 75 & $34(47)$ & 73 \\
\hline $61-70$ & $67(64)$ & 104 & $39(51)$ & 76 \\
\hline $71-80$ & $40(69)$ & 58 & $37(54)$ & 68 \\
\hline $81-90$ & $16(76)$ & 21 & $17(55)$ & 31 \\
\hline Unknown** & $9(75)$ & 12 & $5(38)$ & 13 \\
\hline \multicolumn{5}{|c|}{$\begin{array}{l}{ }^{*} \text { chi-square }=7.90, p=0.004 \text { decrease in the incidence } \\
\text { after intervention, } \\
{ }^{*} \text { age of the patients was not available. }\end{array}$} \\
\hline
\end{tabular}

A higher incidence of potential DDls was observed among the age group of 81-90 years in both the phases. Table 1 categorizes the incidence of DDIs based on the age distribution of the patients. The mean age of the patients who were at higher risk of developing DDIs was 58.80 years $(S D=16.99)$ [Preintervention] and 59.30 years $(S D=17.71)$ [Postintervention]. Male patients encountered a higher number of potential DDIs in both the phases. Altogether $53 \%(n=435$, pre-intervention) and $46 \%$ ( $n=445$, post-intervention) of males encountered DDls.

The details regarding the potential DDIs and the associated diseases are listed in Table 2.

\begin{tabular}{|c|c|c|c|c|}
\hline \multicolumn{3}{|c|}{ Pre-intervention } & \multicolumn{2}{|c|}{ Post-intervention } \\
\hline Diagnosis & $\begin{array}{l}\text { Patients } \\
(\mathrm{n}=435)\end{array}$ & $\begin{array}{l}\text { Risk for } \\
\text { DDIs (\%) }\end{array}$ & $\begin{array}{l}\text { Patients } \\
(n=445)\end{array}$ & $\begin{array}{l}\text { Risk for } \\
\text { DDIs (\%) }\end{array}$ \\
\hline HTN & 149 & $99(66)$ & 111 & $60(54)$ \\
\hline COPD * & 72 & $52(72)$ & 93 & $48(52)$ \\
\hline CVA & 56 & $37(66)$ & 44 & $27(61)$ \\
\hline DM & 48 & $29(60)$ & 34 & $28(82)$ \\
\hline IHD & 25 & $19(76)$ & 32 & $24(75)$ \\
\hline TB & 21 & $17(81)$ & 21 & $13(62)$ \\
\hline $\mathrm{BPH}$ & 24 & $15(63)$ & 21 & $11(52)$ \\
\hline $\mathrm{AF}$ & 14 & $14(100)$ & 19 & $13(68)$ \\
\hline $\mathrm{Ml}$ & 6 & $5(83)$ & 7 & $7(100)$ \\
\hline CCF & 8 & $7(88)$ & 3 & $3(100)$ \\
\hline ALD & 17 & $7(41)$ & 15 & $7(47)$ \\
\hline $\mathrm{RI}$ & 12 & $7(58)$ & 15 & $9(60)$ \\
\hline RHD & 13 & $7(54)$ & 6 & $3(50)$ \\
\hline CRF & 18 & $6(33)$ & 22 & $6(27)$ \\
\hline Cancer & 12 & $5(42)$ & 5 & $1(20)$ \\
\hline ESRD & 8 & $5(63)$ & 1 & $1(100)$ \\
\hline Parkinsonism & 7 & $4(57)$ & 1 & $1(100)$ \\
\hline Miscellaneous & 125 & $56(45)$ & 285 & $96(34)$ \\
\hline \multicolumn{5}{|c|}{$\begin{array}{l}{ }^{*} \text { chi-square }=7.22, p=0.007 \text { decrease in the incidence after } \\
\text { intervention } \\
\text { HTN: hypertension, COPD: chronic obstructive pulmonary } \\
\text { diseases, CVA: cerebrovascular accident, DM: diabetes mellitus, } \\
\text { IHD: ischemic heart disease, TB: tuberculosis, BPH: benign } \\
\text { prostatic hyperplasia, AF: atrial fibrillation, MI: myocardial farction, } \\
\text { CCF: congestive cardiac failure, ALD: alcoholic liver diseases, RI: } \\
\text { renal impairment, RHD: rheumatic heart disease, CRF: chronic } \\
\text { renal failure, ESRD: end stage renal disease. }\end{array}$} \\
\hline
\end{tabular}

According to the Micromedex electronic database classification, most (64\%) of the potential DDIs encountered were of 'Moderate' severity in both the phases, $20 \%$ were of 'minor' type and $16 \%$ were of 'major' type. Onset of most $(58 \%)$ of the potential DDls was of 'Delayed' type followed by rapid (39\% in pre-intervention and $40 \%$ in post-intervention) type in both the phases. The onset of $3 \%$ of potential DDIs in pre-intervention phase and $2 \%$ in post-intervention phase were not specified by the Micromedex. The documentation status of most $(75 \%$ in pre-intervention and $61 \%$ in postintervention) of the potential DDIs was of 'Good' type followed by 'fair' (23\% in pre-intervention and $31 \%$ in post-intervention) and 'excellent' ( $8 \%$ in preintervention and $9 \%$ in post - intervention).

Most of the DDIs encountered during the preintervention phase were pharmacokinetic type $(\mathrm{n}=622,45.18 \%)$ while in the post-intervention most of them were pharmacodynamic $(n=423,41.37 \%)$ type. There was a significant (chi-square $=8.56$, $\mathrm{p}=0.003$ ) reduction in the incidence of pharmacokinetic type of potential DDIs after the intervention.

Cardiovascular drugs were the most common therapeutic category at a high risk for DDIs in pre- 
intervention $(\mathrm{n}=1244,36.09 \%)$ and post-intervention $(n=846,33.21 \%)$ phases respectively. After the intervention there was a significant reduction (chisquare=13.37, $p=0.0003$ ) in the incidence of potential DDls among the drugs acting on Gastro Intestinal Tract (GIT).

Furosemide was the most common high risk drug responsible for DDI in both the phases. Table 3 lists the top fifteen high risk drugs for DDI in pre and post-intervention phases.

Most common DDls during the pre-intervention phase was amlodipine-atenolol ( $n=622,4.82 \%)$. During the post-intervention phase furosemideaspirin ( $n=423,5.20 \%)$ was the most common high risk interacting pair.

\begin{tabular}{|l|c|c|l|c|c|}
\hline \multicolumn{2}{|c|}{ Table 3: High risk drugs for developing DDIs } \\
\hline \multicolumn{1}{|c|}{ Pre intervention } & Number & Percentage & \multicolumn{1}{c|}{ Drugs } & Number & Percentage \\
\hline Durosemide & 118 & 9.40 & Furosemide & 95 & 11.23 \\
\hline Aspirin & 112 & 9.00 & Aspirin & 91 & 10.76 \\
\hline Enalapril & 64 & 5.14 & Phenytoin & 67 & 7.92 \\
\hline Theophylline & 58 & 4.66 & Enalapril & 49 & 5.79 \\
\hline Rifampicin & 56 & 4.50 & Theophylline & 41 & 4.85 \\
\hline Digoxin & 53 & 4.26 & Rifampicin & 30 & 3.55 \\
\hline Warfarin * & 51 & 4.10 & Digoxin & 26 & 3.07 \\
\hline Atenolol & 45 & 3.62 & Ciprofloxacin & 23 & 2.72 \\
\hline Phenytoin ** & 45 & 3.62 & Prednisolone & 21 & 2.48 \\
\hline Amlodipine & 41 & 3.30 & Clopidogrel & 20 & 2.36 \\
\hline Ranitidine & 36 & 2.89 & Amiloride & 19 & 2.25 \\
\hline Isoniazid & 33 & 2.65 & Ramipril & 19 & 2.25 \\
\hline Omeprazole & 26 & 2.09 & Atenolol & 18 & 2.13 \\
\hline Gentamicin & 26 & 2.09 & Metformin & 18 & 2.13 \\
\hline Metformin & 25 & 2.01 & Gentamicin & 18 & 2.13 \\
\hline * Significant (chi-square $=18.26, p<0.01)$ decrease in the incidence after intervention. & \\
** Significant (chi-square $=18.38, p<0.01)$ decrease in the incidence after intervention. & \\
\hline
\end{tabular}

\section{DISCUSSION}

The incidence of potential DDIs during the preintervention phase of our study was $53 \%$. A review of nine epidemiological studies had an increase ranging from $0 \%$ to $2.8 \%{ }^{10}$ Similarly, a study from the United States reported interactions to be responsible for nearly $2 \%$ of adverse event in acute hospitalizations. ${ }^{11}$ A community study including 962,013 prescriptions in Sweden reported an incidence of $13.6 \%{ }^{12}$ Another South Indian study from a community pharmacy reported an incidence of $26 \% .{ }^{13}$ The reason for higher incidence in our study could be due to the inclusion of patients from Internal Medicine wards and ICU, where usually chronically ill and patients with multiple complications requiring polypharmacy are admitted. Following the intervention, we observed a significant reduction in the incidence of potential DDIs. This reduction could be due to less prescribing of potentially interacting drugs such as omeprazole, warfarin and ranitidine.

We found the incidence of potential DDIs was higher in the age group of 81-90 years in the preintervention phase. Conforming to other studies $^{2,12,13}$ we also observed an increase in the number of potential DDls with age. Similarly, a study from Sweden reported $31 \%$ of the DDIs in elderly patients. ${ }^{14}$ In general, elderly patients use more medications. ${ }^{15}$ It has been stated that potential DDIs are common in elderly people using multiple drugs as part of a normal drug regimen. ${ }^{16}$

The present study observed that polypharmacy was common (8.53 drugs per prescription). A study by Smith et al found an ADR rate of $7 \%$ in patients taking 6-10 drugs, increasing to $40 \%$ in those taking
16-20 drugs. This exponential rise was attributed partly to Dls. ${ }^{8}$ A study conducted in the USA found the increase in the risk of adverse drug interactions from $13 \%$ for patients taking two medications to $82 \%$ for those taking 7 or more medications. ${ }^{17}$ In our study, the number of interactions increased with an increase in the number of drugs prescribed. Our study population included both critically ill and elderly patients. Elderly patients require a greater number of drugs.

We found $64 \%$ of the potential DDIs to be moderately severe. 'Major' severity type accounted for $16 \%$ of DDIs and $20 \%$ were of 'Minor' severity. The result of our study is almost similar to the findings of Sabin and coworkers who reported $17.9 \%$ of DDls as potentially minor, $69.9 \%$ as moderate and $12.2 \%$ of major severity. ${ }^{18}$ Our values are higher than the findings reported from a study conducted in the US, which reported $7.3 \%$ of Major DDIs in a surgical intensive care unit. ${ }^{19} \mathrm{~A}$ South Indian study found $15 \%$ of DDIs to be severe in nature and $12 \%$ with a significance level of one (severe reaction and well-documented interaction) which is again higher than our values. ${ }^{13}$

In our study, $58 \%$ of the potential DDIs had a delayed onset as per the Micromedex electronic database. In general, DDIs usually have a specific time course i.e. onset and duration and this makes them more predictable and preventable than ADRs. ${ }^{20}$ This finding suggests that one should be careful while prescribing drugs that can cause delayed type of DDIs. These patients should also be counseled for careful monitoring of symptoms suggestive of the occurrence of DDls. There was no significant reduction in the onset type after the intervention. 
Most of the potential DDIs in our study had a 'Good' documentation status (70\%) thus with the sound knowledge and information of DDIs, these DDIs can be predicted and hence prevented. During the preintervention phase, higher number of pharmacokinetic interactions was seen. Unlike our finding, studies have identified that, the most common interactions encountered in clinical practice are pharmacodynamic. ${ }^{21,22}$ The number of pharmacodynamic interactions was higher in the post-intervention phase. This could be because after the intervention, drugs responsible for causing pharmacokinetic interactions like ranitidine, omeprazole, warfarin and alprazolam were prescribed less commonly. This may also be attributed to the intervention where unnecessary uses of drugs like ranitidine and omeprazole were discouraged.

In our study cardiovascular drugs were the predominant class of drugs at a high risk for DDIs followed by antimicrobials. Similar to our findings, a study from England reported cardiovascular drugs as the major drugs involved in ADRs. ${ }^{23}$ In cardiovascular diseases, polypharmacy cannot be ignored. For example the recent JNC VII guidelines recommends polypharmacy in managing diseases like hypertension. ${ }^{2}$ Moreover, conditions like hypertension are associated with other concurrent complications that might increase the risk of potential DDIs.

A study by Doucette and coworkers also found cardiovascular and psychotropic medications to be more frequently involved in DDIs. ${ }^{24}$ In general, Internal Medicine wards include significant number of cardiac patients in our hospital. This could be a reason attributable for the higher number of cardiac drugs in our study.

During the pre-intervention phase, furosemide $(9.4 \%)$ followed by aspirin $(9.0 \%)$, enalapril $(5.14 \%)$, theophylline $(4.66 \%)$ and rifampicin $(4.50 \%)$, were the drugs at a high risk for developing DDIs. A South Indian study identified antitubercular drugs, analgesics and antipyretics, bronchodilators, diuretics, antiplatelet drugs, H2-receptor blockers and proton pump inhibitors as commonly responsible for causing DDls. ${ }^{14}$ Digoxin and cimetidine were the potential interacting drugs in almost $90 \%$ of the cases in a study done in surgical patients and critically ill patients. ${ }^{25}$ Though some of the drugs involved are similar, our study has focused mainly on the interaction pattern of drugs used in the internal medicine wards. This might have influenced the type of drugs involved in DDIs.

The most common drugs responsible for potential DDls during post-intervention phase were furosemide, followed by aspirin, phenytoin, enalapril and theophylline. The change (increase) after intervention was significant for phenytoin. These drugs are in general, commonly used in Internal Medicine wards hence their involvement in DDIs are also common. We could not find any interventional studies related to this matter to support our result.

The most common potential DDls observed during the pre-intervention phase were between amlodipine and atenolol (4.82\%) followed by furosemide and aspirin (4.02\%). Unlike in our finding, a study done in an elderly population found that the most common DDls were between betablockers and antidiabetics, followed by potassiumsparing diuretics and potassium, and carbamazepine and dextropropoxyphene. ${ }^{14}$ In a prospective analysis of 18820 patients, aspirin with warfarin, aspirin with other NSAIDs, combinations of diuretics or the concomitant use of diuretics and ACEIs, digoxin toxicity through co-prescription of interacting drugs were the common causes for admission to the hospital due to ADRs. ${ }^{23}$ During the post-intervention phase, the most common potential DDIs identified were between furosemide and aspirin $(5.20 \%)$ followed by enalapril and furosemide $(4.49 \%)$.

The findings of this study however cannot be generalized due to several reasons. The study does not include patients from other wards of the hospital where the incidence and pattern of DDls may be different. The identification of the DDIs in our study was based on the Micromedex electronic database and we did not confirm our findings by measuring the plasma drug concentration of the interacting drugs. Moreover, the clinical outcomes of the patients were not documented by us.

\section{CONCLUSIONS}

The study found the association of potential DDIs with parameters like age, sex, number of drugs per prescription. Cardiovascular drugs accounted for higher number of potential DDIs and furosemide was the high risk drug responsible for DDIs. There was a direct link between polypharmacy and occurrence of DDIs. The study concluded that educational interventions can minimize the incidence of DDIs.

\section{ACKNOWLEDGEMENTS}

The authors acknowledge Mr. V.S. Binu, Biostatistician, Department of Community medicine, Manipal College of Medical Sciences, Pokhara, Nepal for helping in the statistical aspects of the study.

\section{CONFLICT OF INTEREST}

None.

\section{References}

1. Lee A, Stockley IH. Drug interactions In: Walker R, Edwards C. Clinical Pharmacy and Therapeutics. 3rd edition. Churchill Livingstone, Philadelphia 2003: 21-31.

2. Chobanian AV, Bakris GL, Black HR, Cushman WC, Green LA, Izzo JL Jr, Jones DW, Materson BJ, Oparil S, Wright JT Jr, Roccella EJ; National Heart, Lung, and Blood Institute Joint National Committee on Prevention, Detection, 
Evaluation, and Treatment of High Blood Pressure; National High Blood Pressure Education Program Coordinating Committee. The seventh report of the joint national committee on prevention, detection, evaluation, and treatment of high blood pressure. The JNC 7 report. J Am Med Assoc. 2003;289:2560-2572.

3. Boston Collaborative Drug Survelliance Program: Adverse drug interactions. J Am Med Assoc. 1972;220:1238-1239.

4. Classen DC, Pestotnick SL, Evans RS, Bukke JP. Computerized surveillance of adverse drug events in hospital patients. J Am Med Assoc. 1991;266:2847-2851.

5. Grymonpre RE, Mitenko PA, Sitar DS, Aoki FY, Montgomery PR. Drug-associated hospital admissions in older medical patients. J Am Geriatr Soc. 1988;36:1092-1098.

6. Stockley IH. Drug interaction: a source book of adverse interaction, their mechanisms, clinical importance and management.5th ed. Pharmaceutical Press, London 1999.

7. Smith JW, Seild L G, Cluff L E. Studies on the epidemiology of adverse drug reactions. V. Clinical factors influencing susceptibility. Ann Intern Med. 1969;65:629.

8. Joshi MP, Sugimoto T, Santoso B. Geriatric prescribing in the medical wards of a teaching hospital in Nepal. Pharmacoepidemiol Drug Saf. 1997;6:417-421.

9. Thomson Micromedex, Greenwood Village, Colorado (Edition expires [6/2006])

10. Jankel CA, Fitterman LK. Epidemiology of drug-drug interactions as a cause of hospital admissions. Drug Saf. 1993;9:55-59.

11. Leape LL, Brennan TA, Laird N, Lawthers AG, Localio AR, Barnes BA, Hebert L, Newhouse JP, Weiler PC, Hiatt H. The nature of adverse events in hospitalized patients: results of the Harvard Medical Practice Study II. N Engl J Med. 1991;324(6):377-384.

12. Merlo J, Liedholm H, Lindblad U, Björck-Linné A, Fält J, Lindberg G, Melander A. Prescriptions with potential drug interactions dispensed at Swedish pharmacies in January 1999: cross sectional study. BMJ. 2001;323:427-428.

13. Nagavi BG, Singhal R. Drug interactions in prescription from selected Indian community pharmacies. J Pharm Pract Res. 2005;35:332.

14. Bergendal L, Friberg A, Schaffrath AM. Potential drug-drug interactions in 5,125 mostly elderly out-patients in Gothenburg, Sweden. Pharm World Sci. 1995;17:152-157.

15. Stewart RB, Cooper JW. Polypharmacy in the aged. Practical solutions. Drugs Aging. 1994;4:449-461.

16. Biorkman IK, Fastbom J, Schmidt IK, Bernsten CB. Drug-drug interactions in the elderly. Ann Pharmacother. 2002;36:1675-1681.

17. Goldberg RM, Mabee J, Chan L, Wong S. Drug-drug and drug-disease interactions in the ED: analysis of a high-risk population. Am J Emerg Med. 1996;14;447-450.

18. Egger SS, Drewe J, Schlienger RG. Potential drug-drug interactions in the medication of medical patients at hospital discharge. Eur J Clin Pharmacol. 2003; 58:773-8.

19. Oeser DE, Polansky M, Thomas NP, Varon J. Incidence of major drug interactions and associated adverse drug events in a surgical intensive care unit. Internet J Pharmacol. 2003;2.

20. Johnson MD, Newkirk G, White JR Jr. Clinically significant drug interactions: what you need to know before writing prescriptions. Postgrad Med. 1999;105:193-206.

21. Chadwick B, Waller DG, Edwards JG. Potentially hazardous drug interactions with psychotropics. Advances in Psychiatric treatment. 2005;11:440-449.

22. Hussar DA. Drug interaction. In: Gennaro, Marderosian AHD, Hanson GR et al. Remington The science and practice of pharmacy. Philadelphia: Lippincott Williams \& Wilkins, 2000: 1746-1761.

23. Pirmohamed M, James S, Meakin S, Green C, Scott AK, Walley TJ, Farrar K, Park BK, Breckenridge AM. Adverse drug reactions as cause of admission to hospital: prospective analysis of 18820 patients. BMJ. 2004;329:15-19.

24. Doucet J, Chassagne P, Trivalle C, Landrin I, Pauty MD, Kadri N, Ménard JF, Bercoff E. Drug-drug interactions related to hospital admissions in older adults: a prospective study of 1000 patients. J Am Geriatr Soc. 1996;44:944-948.

25. Durrence CW 3rd, DiPiro JT, May JR, Nesbit RR Jr, Sisley JF, Cooper JW. Potential drug interactions in surgical patients. Am J Hosp Pharm. 1985;42:1553-1556. 